\title{
Use of dynamic energy budget and individual based models to simulate the dynamics of cultivated oyster populations
}

\author{
Cédric Bacher $^{\mathrm{a},{ }^{\star}}$ and Aline Gangnery ${ }^{\mathrm{b}}$
}

\author{
IFREMER, BP 70, 29280 Plouzané, France \\ ${ }^{\mathrm{b}}$ IFREMER, Laboratoire Environnement Ressources de Normandie, Avenue du Général de Gaulle, BP \\ 32, 14520 Port en Bessin, France
}

*: Corresponding author : cbacher@ifremer.fr

\begin{abstract}
:
We successfully tested a Dynamic Energy Budget (DEB) model of the oyster Crassostrea gigas using published environmental data and growth data collected in Thau lagoon (France). Estimates of most DEB parameters were based on independent datasets and only two parameters were calibrated using our datasets: the shape parameter, which was used to convert body volume into shell length, and the half-saturation coefficient, which controlled the functional response of assimilation to food concentration, represented by chlorophyll-a concentration. The DEB model proved to be robust and generic: it was able to reproduce oyster growth in Thau lagoon and other ecosystems. We also assessed population dynamics by coupling DEB equations and an Individual Based Model (IBM) of cultivated oyster populations. The results were compared with previously published simulations of harvested production and standing stock based on an empirical growth equation and a partial differential equation of population dynamics. Differences between the two studies were explained by the difference between the predictions of oyster growth with the empirical and the DEB models. We also accounted for growth variability between individuals and showed that IBM offers a powerful alternative to continuous equations when several physiological variables are involved.
\end{abstract}

Keywords: Crassostrea gigas; Dynamic energy budget; Harvested production; Growth variability; Thau lagoon 


\section{Introduction}

Individual growth is the main process accounted for by mathematical models of living organisms and an abundant literature deals with the simulation of individuals mass or size and focus on energy budget. This is also true for marine filter feeders and effort has been put for many years on the mathematical formulation and parameterisation of energy gain and expenditure in order to predict individual growth in a varying environment (Ross and Nisbet, 1990; Van Haren and Kooijman, 1993; Barillé et al., 1997; Pastres et al., 2001; Rueda et al., 2005). In this context, models based on Dynamic Energy Budget (DEB) concepts (Kooijman, 2000) aim at deriving a generic set of equations from general properties of living organisms and represent a promising tool (Beadman et al., 2002). When population dynamics of filter feeders is concerned several strategies can be applied. Age distribution is commonly used to describe the survival of individuals (Savina, 2004). Size and mass distributions have also been considered by several authors who assessed the relationship between biomass and environmental factors or management strategies (Barbeau and Caswell (1999) for Placopecten magellanicus, Dekshenieks et al. (2000) for Crassostrea virginica, Pastres et al. (2001) for Tapes philippinarum, Borja and Bald (2002) for Ruditapes decussatus, Duarte et al. (2003) for Chlamys farreri, Gangnery et al. (2004a,b) for Crassostrea gigas and Mytilus galloprovincialis). In these models, the transition between classes is derived from the equation of individual growth and it is generally assumed that individuals who belong to the same class have the same growth - though inter-individual variability has been superimposed by Gangnery et al. (2004a,b). One difference between these models concerns the number of size/mass classes but all models use a single variable to represent individual growth. For instance Gangnery et al. (2004a) simulate individual total mass and compute the number of individuals in ca. 90 mass classes with a partial differential equation (referred as PDE in the text) in which an empirical growth equation is used to compute the transition between classes. In more complex growth model like DEB, individuals can not be represented by a single variable - e.g. total mass. As explained in this volume, the utilisation of energy by an individual for growth, maintenance and reproduction involves at least 3 compartments: storage, body volume and reproduction. Shell length is directly related to body volume whose dynamics results from energy flows between all 3 compartments. The use of DEB models to reproduce population dynamics would therefore imply to replace the transition between adjacent mass classes by transitions between storage, body volume and reproduction classes in a way similar to Gangnery et al. (2001) and it would require solving a PDE with partial derivatives with respect to these 3 variables. Numerical integration of such an equation is less straightforward than the PDE used by Gangnery et al. (2001). Alternative methods presented in DeAngelis and Gross (1992) are called Individual Based Models (IBM). The population is divided into cohorts and its dynamics is reproduced by simulating the growth trajectories of numerous individuals. Standing stock is obtained by summing up individual mass and the size distribution of individuals approximates the real size distribution. Since the recruitment of new individuals in the population is linked to individual reproduction and is sensitive to the 
approximation of the true size distribution, special algorithms have been applied to ascertain that this approximation is acceptable (De Roos, 1988; Hallam et al., 1988). Since IBMs are easier to implement than PDE, especially in the case where several physiological variables are needed to represent the population structure, they are applied in various fields (De Roos et al., 1997; Wyszomirski et al., 1999; McDermot and Rose, 2000; De Roos and Persson, 2001; Batchelder et al., 2002). They allow tracking individual history and accounting for interactions between individuals when they exist. On the other hand, such methods often require intensive computations due to the large number of cohorts needed to account for temporal and spatial variability and/or populations interactions (Batchelder et al., 2002).

In this paper we present a population model based on an IBM method using DEB model to simulate individual growth and reproduction. We applied this population model to the case of cultivated oyster populations in Thau lagoon documented by Gangnery et al. (2003, 2004a). Briefly, Thau lagoon is an important shellfish culture area of Pacific oysters (Crassostrea gigas) and Mediterranean mussels (Mytilus galloprovincialis). The total standing stock varies between 14,000 and 20,000 tons ( 1 ton $=1000 \mathrm{~kg}$ ) a year (Gangnery et al., 2001) and oysters account for about three quarters of the total cultured biomass. The population dynamics model developed by Gangnery et al. (2004a) is based on a PDE of oyster abundance accounting for individual growth rate, inter-individual growth variability, seeding, harvesting and natural mortality rates. Growth is simulated with an empirical equation in which growth rate is a function of water temperature, particulate organic matter concentration and individual total mass. The model took into account two culture methods and rearing strategies of oyster farmers by using timetables of seeding and harvesting and was calibrated on observed distributions of standing stocks. The model was used to evaluate the effects of different environmental conditions - e.g. a decrease in the oyster growth rate, a harvesting closure due a toxic algae bloom, a massive summer mortality due to an anoxic crisis, on short- and long-term variations in the standing stock and harvested production. By construction, the empirical growth equation was unable to compute the amount of food used by the oyster population and only a mechanistic model based on energy budget would allow to fully addressing the interactions between oyster population and ecosystem.

Our objectives were therefore: i) to reproduce the observed growth of Pacific oysters in Thau lagoon with a generic model already calibrated and validated on other data sets (Pouvreau et al., 2006; Van der Veer et al., 2006), ii) to switch from a PDE-based model to an IBM incorporating the DEB physiological variables in the simulation of the population dynamics and oyster production assessment, iii) to enable to link the ecosystem functioning and the oyster population dynamics in a way that will allow to assess the effect of ecosystem changes on oyster production.

\section{Methods}

\subsection{Dataset}

Environmental and oyster growth data were published by Gangnery et al. (2003). In order to 
estimate trophic resources potentially available for oysters, suspended particulate matter (total, organic and inorganic fractions) and phytoplankton biomass (total and size-fractionated chlorophyll a) were estimated. Samples were taken every two weeks at 4 sites from March 2000 until October 2001 (Fig.1). Other environmental data, temperature and salinity, were also sampled with the same frequency. Food was expressed as total chlorophyll a concentration. Temperature and chlorophyll a concentration were therefore the 2 variables used in the model as driving functions (see DEB model below and Fig. 2). Oysters were set on ropes used for culture on two occasions (i.e. two seeding dates) in late March 2000 and late September 2000 and using two different cultivation techniques (called 'categories' in the following; see Gangnery et al., 2003 for details about the culture techniques) at the same four sites. Ultimately, 16 experimental growth curves were obtained (2 seeding dates, 4 sites, 2 categories). Growth was monitored monthly during spring and summer and every two months during fall and winter during 1 year. On each occasion, one rope of oysters was sampled and a sub-sample of 30 individuals was randomly chosen in order to assess growth average as well as variability. Shell length $(L, \mathrm{~mm})$, individual total mass $(W T, \mathrm{~g})$ and fresh tissue mass $(W, g)$ were measured on every individual. In the following the 16 time series of environmental and growth data will be referred as datasets combining 2 seeding dates, 4 sites and 2 categories.

Since oysters are cultured populations, seeding is not directly linked to oyster abundance or reproduction. Small oysters are usually imported from other cultivated areas or produced by hatcheries. The main seeding occurs between January to April and to a lesser extent in fall (Gangnery et al., 2004a). Seeding is avoided in summer (July and August) when high temperatures implied stressful conditions and seeding rates are also low in December when the farmers activity turns to the Christmas sale season. For our modelling issue, seeding refers to the number of seeded animals set up every month. Harvest depends on both individual mass and season. Information on monthly frequencies of harvest shows that peak periods are December, July and August. Similar as in Gangnery et al. (2001, 2004a) dependency upon mass has been taken into account with a sigmoid function and harvest was introduced in the model as a daily fraction of the number of individuals which have a mass above a given value. Seeding and harvesting timetables were obtained from information given by farmers while the numbers of seeded animals per month were obtained through calibration with the PDE-based model (Gangnery et al., 2004a).

\subsection{DEB model}

We kept most of the equations and parameters similar to those listed and estimated by Pouvreau et al. (2006), Van der Meer (2006) and Van der Veer et al. (2006). They are based on Kooijman (2000) DEB theory and have already been applied by Van Haren and Kooijman (1993) to Mytilus edulis, Van der Veer et al. (2001) to flatfishes and Cardoso et al. (2001) to several benthic bivlave species. Parameters are listed in Table 1 and equations are briefly described below. The 
notation and symbols follow those in Kooijman (2000) whereby the following main rules apply:

1. variables are indicated by symbols and lower case symbols frequently relate to upper case ones via scaling;

2. quantities are expressed per unit of volume with square brackets []; per unit of biosurface area with braces \{\} ; and per unit of mass with angles $<>$;

3. rates have dots, indicating the dimension per time.

The dynamics of growth and reproduction were represented by differential equations of three state variables: structural body volume $\mathrm{V}\left(\mathrm{cm}^{3}\right)$, energy reserves $\mathrm{E}(\mathrm{J})$ and energy allocated to development and reproduction $\mathrm{R}(\mathrm{J})$.

For a single food source, assimilation energy rate is a function of food density $\left([X], \mathrm{mg} . \mathrm{I}^{-1}\right)$ and is proportional to surface area of the structural body volume, which corresponds to the part of tissue without gonads and reserves. It is equal to:

$$
\dot{p}_{A}=\left\{\dot{p}_{A m}\right\} \cdot f \cdot V^{2 / 3} \quad\left(\mathrm{~J}^{-\mathrm{d}^{-1}}\right)
$$

with $f=\frac{[X]}{[X]+X_{K}}$

where $f$ is the functional response of assimilation to food concentration (dimensionless), $X_{K}$ is the half saturation coefficient ( $\mu \mathrm{g}$ chlorophyll a. $\left.\right|^{-1}$ ) and $\left\{\dot{p}_{A m}\right\}$ is the maximum surface area-specific assimilation rate $\left(\mathrm{J} . \mathrm{cm}^{-2} \mathrm{~d}^{-1}\right)$. Assimilation contributes to the dynamics of the energy reserves which are given by the equation:

$$
\frac{d E}{d t}=\dot{p}_{A}-\dot{p}_{C}
$$

where $\dot{p}_{C}\left(\mathrm{~J} . \mathrm{d}^{-1}\right)$ denotes the energy utilisation rate. For the change of the structural volume it is assumed that a fraction of the utilisation rate is used for maintenance and structural growth and that maintenance rate is proportional to the volume. Therefore:

$$
\frac{d V}{d t}=\frac{\kappa \cdot \dot{p}_{C}-\left[\dot{p}_{M}\right] \cdot V}{\left[E_{G}\right]} \quad\left(\mathrm{cm}^{3} \cdot \mathrm{d}^{-1}\right)
$$

where $\left[\dot{p}_{M}\right]$ is the maintenance cost $\left(\mathrm{J}_{\mathrm{cm}} \mathrm{cm}^{-3} \cdot \mathrm{d}^{-1}\right),\left[E_{G}\right]$ is the volume-specific cost for structure $\left(\mathrm{J} . \mathrm{cm}^{-}\right.$ $\left.{ }^{3}\right)$, and $\kappa(-)$ is the fraction of energy utilisation rate spent on maintenance plus growth. Kooijman (2000) derived the following equation of energy utilisation from theoretical considerations:

$$
\dot{p}_{C}=\frac{[E]}{\left[E_{G}\right]+\kappa \cdot[E]}\left(\frac{\left[E_{G}\right] \cdot\left\{\dot{p}_{A m}\right\} \cdot V^{2 / 3}}{\left[E_{m}\right]}+\left[\dot{p}_{M}\right] \cdot V\right)
$$

where $[E]$ represents energy density $\left([E]=\frac{E}{V},{\mathrm{~J} . \mathrm{cm}^{-3}}^{-3}\right.$ and $\left[E_{m}\right\rfloor$ is the maximum energy density in the reserve compartment. Substituting $\dot{p}_{C}$ in differential equations of $\mathrm{V}$ and $\mathrm{E}$ allows to simulate these two state variables as a function of food concentration.

Assimilation and maintenance rates depend on temperature with an Arrhenius-type equation extended to include a species-specific tolerance range for low and high temperatures (Kooijman, 2000; Van der Veer et al., 2006). Assimilation and maintenance rates at temperature $T$ 
(K) are derived from the rates at the reference temperature $T_{1}$ using the following formulations:

$$
\begin{aligned}
& {\left[\begin{array}{l}
\dot{p}_{M}(T)
\end{array}\right]=\left[\begin{array}{ll}
\dot{p}_{M}\left(T_{1}\right)
\end{array}\right] \cdot f(T) \quad\left({\left.\mathrm{J} . \mathrm{d}^{-1}\right)}^{-1}\right.} \\
& \left\{\dot{p}_{A m}(T)\right\}=\left\{\dot{p}_{A m}\left(T_{1}\right)\right\} \cdot f(T) \quad\left({\left.\mathrm{J} . \mathrm{d}^{-1}\right)}^{-1}\right. \\
& f(T)=\exp \left\{\frac{T_{A}}{T_{1}}-\frac{T_{A}}{T}\right\} \cdot\left(1+\exp \left\{\frac{T_{A L}}{T}-\frac{T_{A L}}{T_{L}}\right\}+\exp \left\{\frac{T_{A H}}{T_{H}}-\frac{T_{A H}}{T}\right\}\right)^{-1}
\end{aligned}
$$

where $T_{A}$ is the Arrhenius temperature $(\mathrm{K}), T_{L}$ is the lower boundary of tolerance range, $T_{H}$ is the upper boundary of tolerance range and $T_{A L}$ and $T_{A H}$ are Arrhenius temperatures $(\mathrm{K})$ for the rate of decrease at both boundaries.

Juvenile development (i.e. increase in state of maturity) and adult reproduction (i.e. gamete production and spawning) correspond to 2 different stages in the individual life history. The transition between juveniles and adults implies a change in the maintenance rate. Kooijman (2000) introduced a threshold value of the structural volume $V_{P}$ which marks the transition between development and gamete production and showed that:

$$
\frac{d R}{d t}=(1-\kappa) \cdot \dot{p}_{C}-\left(\frac{1-\kappa}{\kappa}\right) \cdot \min \left(V, V_{p}\right) \cdot\left[\dot{p}_{M}\right] \quad\left(\mathrm{J}^{-\mathrm{d}^{-1}}\right)
$$

According to Pouvreau et al. (2006), spawning was triggered when the ratio between gonad and total tissue mass and water temperature were above 0.35 and $20^{\circ} \mathrm{C}$, respectively. Then, in these occasions, compartment $R$ was totally emptied.

Shell length $L(\mathrm{~cm})$ was obtained from body volume using an allometric function:

$$
L=\frac{V^{1 / 3}}{\delta_{m}}
$$

where $\delta_{m}$ is the shape coefficient, estimated by Van der Veer et al. (2006) from independent datasets, however we also estimated $\delta_{m}$ from our simulations to test the assumption that this parameter is specific to species and not to sites.

\subsection{Simulation of growth surveys}

In order to apply DEB model to datasets, first the half saturation coefficient $X_{k}$ (Eq. 1b) and the shape coefficient $\delta_{m}$ (Eq. 9) were calibrated for each dataset using observed shell length and fresh tissue mass and measurements of temperature and chlorophyll a (see 2.1) as forcing functions. For all datasets, also a single $X_{k}$ and a separate $\delta_{m}$ was estimated in order to test if the goodness of fit was sensitive to this parameter. Calibration procedure was carried out by minimising the mean relative difference between simulated and observed fresh tissue mass and shell length with the Nelder-Mead simplex method implemented in Matlab ${ }^{\circledR}$. Fresh tissue mass $W$ (g) was obtained by summing the 3 variables $E(\mathrm{~J}), V\left(\mathrm{~cm}^{3}\right)$ and $R(\mathrm{~J})$ after conversion into fresh 
mass. As in Pouvreau et al. (2006), $E$ was converted using the parameter $\mu_{E}$. $R$ was firstly transferred into gametes with an efficiency $\kappa_{R}$ (Pouvreau et al., 2006) and then converted into mass using the parameter $\mu_{E}$. A specific mass $\rho$ of $1 \mathrm{~g} . \mathrm{cm}^{-3}$ was used to convert volume $V$ into mass:

$W=\frac{E}{\mu_{E}}+\frac{\kappa_{R} \cdot R}{\mu_{E}}+V \cdot \rho$

When comparing simulated and observed growth data, one difficulty was to determine the initial values of the 3 state variables. Since growth surveys always started with small individuals with a total mass less than $8 \mathrm{~g}$, we assumed that $R$ was equal to 0 . Initial tissue mass had therefore to be split between structural volume and storage, and estimations were obtained after several calibration trials - but no automatic procedure was applied. The repartition used in the simulations is presented in Table 2.

For the simulation of standing stock and harvested production (see explanations below), the individual total mass WT (shell + fresh tissue, g) needed to be estimated. It was derived from shell length by an empirical relationship based on data from Gangnery et al. (2003):

$W T=0.0934 \cdot L^{3}$

\subsection{Sensitivity analysis}

A sensitivity analysis was conducted on several parameters to assess their impact on the model results. Each parameter was modified by $+10 \%$ and the results of each run were analysed using a sensitivity index $(\mathrm{SI})$ to calculate the resulting percentage change in the fresh tissue mass:

$S I=\frac{1}{n^{t=1}} \sum^{n} \frac{\left|W_{t}^{1}-W_{t}^{0}\right|}{W_{t}^{0}} \cdot 100$

where $\mathrm{n}$ is the number of simulated days, $W_{t}^{0}$ is the fresh tissue mass predicted with the standard simulation at time $t$, and $W_{t}^{1}$ is the fresh tissue mass predicted with a new parameter value at time $t$. A mean value of $\mathrm{SI}$ was calculated over the 4 sites for each combination survey $\mathrm{x}$ category.

\subsection{Model of individual variability}

Since measurement of growth variability showed that variability between individuals played an important role in the population dynamics (Gangnery et al., 2001, 2004a), a random effect was incorporated in the DEB model. It was assumed that variability would mainly affect the half saturation coefficient $X_{k}$ (Eq. 1b) for two reasons: $X_{k}$ was already a parameter calibrated for the different surveys, categories and sites in order to account for differences between growth time series, and it was also more straightforward to consider a single parameter - and probably efficient enough with regards to the prediction of variability. We therefore estimated by trial and error which 
random noise of the calibrated $X_{k}$ would reproduce the observed standard deviations of shell length and fresh tissue mass. Assuming a normal distribution of $X_{k}, 100$ simulations of individual growth were run with randomly drawn $X_{k}$ values for each growth time series. Predicted standard errors were plotted against observed standard errors. The standard deviation parameter of the normal distribution was changed by trial and error until a satisfactory correlation between predicted and observed standard errors was obtained.

\subsection{Population model}

Several cohorts were defined to simulate the population dynamics. Denoting $N_{i}$ the number of individuals in cohort $i$, we solved the following differential equation:

$$
\frac{d N_{i}}{d t}=-h_{i} \cdot N_{i}-m_{i} \cdot N_{i} \quad\left(\text { ind. } d^{-1}\right)
$$

where $h_{i}$ is the harvest rate coefficient and $m_{i}$ is the natural mortality rate coefficient. The harvest rate was a function of time and individual mass (see above) and mortality rate was defined as a constant $\left(0.1 \mathrm{yr}^{-1}\right.$, Gangnery et al., 2004a). Initial values of $N_{i}$ were given by the seeding timetable (see 2.1) according to a seeding time interval $\Delta t$. Physiological variables $V_{i}, E_{i}, R_{i}, L_{i}$ and $W T_{i}$ were associated to cohort $i$ and simulated with the DEB equations explained above. As Gangnery et al. (2004a), spatial variability of environmental conditions and growth was neglected and temperature and chlorophyll a time series were averaged. Also the value of the shape parameter was kept similar to Van der Veer et al. (2006) and the half saturation coefficient used in the functional response of assimilation to food concentration was averaged. Initial values of physiological variables were the same as for the simulations of the growth surveys (see 2.3). $L_{i}$ and $W T_{i}$ were derived from the previous variables using the shape parameter (conversion from body volume to shell length - Eq. 9) and length to total mass conversion coefficient (Eq. 11).

All differential equations were integrated simultaneously using an Euler algorithm with a time step of one day. At every time step all cohorts were summed up to estimate standing stock as a function of time with the following equation:

$$
S=\sum_{i} N_{i} \cdot W T_{i}
$$

Harvested production was defined as the cumulative harvest of cohorts:

$P=\sum_{i} h_{i} \cdot N_{i} \cdot W T_{i}$

and the total number of oysters was equal to:

$N=\sum_{i} N_{i}$

Initial numbers of individuals, cohorts and standing stock were set to 0 . Simulations were therefore run during several years in order to reach stable standing stock and harvested production variations. For that purpose, environmental forcing (see 2.1 and 2.3) of individual growth and 
seeding/harvest timetables (see 2.1) were repeated during several years. Due to rapid oyster growth, oysters reach the marketable mass after roughly one year (Gangnery et al., 2004a) which means that a cohort lifespan was ca. 1 year and simulated standing stock and harvested production were stable after ca. 3 years.

Simulating the population dynamics with a finite number of cohorts is an approximation of the real dynamics and approximations of mass distribution, standing stock and harvested production depend on the seeding time interval - e.g. number of cohorts. Several seeding time intervals were tested before satisfactory results were obtained that were assessed in two different ways. To check IBM consistency, we first implemented Gangnery's empirical growth equation (Gangnery et al., 2004a) instead of the DEB model into the IBM and compared standing stocks and harvested production yielded by Gangnery's PDE-based model and our IBM with different seeding time intervals. Also DEB-IBM simulations with different seeding time intervals were compared to assess below which values simulations would show a difference lower than $1 \%$ - an arbitrary value that we judged small enough for the accuracy we aimed at in our estimation of harvested production. In all cases, it was found that a seeding time interval of one day was small enough. Around 1000 growth trajectories were therefore simulated to reproduce the population dynamics during 3 years.

By combining the variability of $X_{k}$ derived from the estimation on the 16 datasets as well as inter-individual growth variability, inter-individual variability was introduced in the population model. Each cohort had a random $X_{k}$ and standing stock and harvested production were calculated as above. 50 simulations were run and statistics of stock and harvested production were derived from the model outputs.

\section{Results}

\subsection{Simulation of growth surveys}

The calibration of a single parameter $X_{k}$ for the whole datasets led to a poor fit between simulated and observed values of the fresh tissue mass (Fig. 3). The optimised value obtained for $X_{k}$ is 2.97. After calibration of $X_{k}$ and $\delta_{m}$ on each of 16 growth datasets, simulations fitted well to observed fresh tissue mass, shell length and total mass with an average relative error lower than $10 \%$ (Figs $4-7$ ). $X_{k}$ ranged from 2.01 to 3.91 and $\delta_{m}$ from 0.158 to 0.206 with average values equal to 2.96 and 0.19 for the 2 parameters, respectively (Table 3). The functional response (Eq. 1b) of assimilation rate to food concentration (measured chlorophyll a) was comprised between 0.1 and 0.56 which showed that growth was food-limited.

For fresh tissue mass during survey 1 , the general features were well captured by the calibration of the 2 DEB parameters. For category 1 for instance mass grew from less than $1 \mathrm{~g}$ up to between 8 and $14 \mathrm{~g}$ depending on the sites (Fig. 4a) and, for the second category, mass varied from ca. $0.3 \mathrm{~g}$ in May to $4-7 \mathrm{~g}$ after one year (Fig. 5a). Differences between sites were important 
and comparable for both categories. The functional response of assimilation to food concentration captured partly these differences, which were also reflected by the different values of $X_{k}$ obtained for each site. The general trend of mass variation was marked by a seasonal effect related to temperature, with low growth during winter and maximum growth between July and September. The model estimated one spawning event for category 1 only, which occurred in mid-September. For survey 2, observed tissue masses were correctly predicted except for category 1 where the mass was overestimated at the end of the growth experiment (Fig. 6a). The model estimated one or two spawning events depending on the site and for category 1 only. The first one occurred in May-June and the second one in July-August.

For all surveys and categories, observed shell lengths displayed a plateau from November to January and maximum changes occurred during spring and summer (Figs 4b-7b). This was generally well reproduced by the simulations in all surveys but some differences were noticed for small individuals in survey 1 and category 2 (e.g. the model overestimated the length) and in survey 2 and category 1 (e.g. the model overestimated length of large individuals).

As opposed to shell length, predicted total mass was correct for all surveys and categories except for survey 2 and category 1 where mass of individuals was generally underestimated (Figs 4c-7c). Despite these occasional differences between simulations and observations, correlations between predicted and observed values were very close to 1 ( 0.98 for fresh tissue mass, 0.97 for shell length and 0.95 for total mass). The slope of the fitted regression between simulated and observed values was not different from 1, which showed that the model was not biased (Fig. 8).

Sensitivity analyses showed that the parameters governing food consumption, i.e. $\left\{\dot{p}_{A m}\right\}$ and in a lesser extent $X_{k}$, and parameter $\kappa$, had the most important effect on the growth in fresh tissue mass. An increase of $10 \%$ in $\left\{\dot{p}_{A m}\right\}$ and $\kappa$ yielded a mean variation of 11 to $22 \%$ depending on the combination survey $x$ category, in the fresh tissue mass (Fig. 9). An increase of $10 \%$ in the parameter $X_{k}$ yielded a variation of ca. $10 \%$ in the fresh tissue mass. On the contrary, parameters $\left[E_{G}\right], V_{p}$ and initial conditions of mass repartition between structural volume, reserves and gonad had small effects (ca. 1\%) on the predicted fresh tissue mass.

\subsection{Model of individual variability}

Taking into account the variability between individual growth resulted in an estimation of $X_{k}$ standard deviation of ca. $24 \%$, all sites and surveys combined. Simulating variable growth trajectories with randomly drawn $X_{k}$ values reproduced well observed standard deviations of fresh tissue mass (Fig. 10).

\subsection{Simulation of the population}

For the DEB-IBM, the average values of $X_{k}$ and $\delta_{m}$ were used first, whereby stock and 
harvested production was plotted after simulations reached an equilibrium. Simulation started with no oyster at all, and it was checked that the simulation of standing stock and harvested production did not depend on the initial condition by running and comparing several simulations. At equilibrium, simulated standing stock varied between $\mathrm{ca}$. 3,800 tons and 7,000 tons, with a maximum value at the end of summer and an average of 4,623 tons (Fig. 11). Harvest started very slowly and had a sharp increase when the stock started to decrease. The maximum harvested production was equal to 5,561 tons at the end of the year. The values can be compared to the simulation of the PDE-based model under the same conditions (Gangnery et al., 2004a) with and without inter-individual variability. In the first case, we kept the numerical diffusion as well as the diffusion coefficient to reproduce the variability between individual growth. In the second case, the diffusion coefficient was set to 0 and the numerical diffusion was set to a minimum by decreasing the size of the mass classes (see Gangnery et al., 2001, 2004a for more information on the method used to solve the PDE). While the annual harvested production was about the same (e.g. 5,820 tons with diffusion, 5,753 tons without diffusion), the curves of harvested cumulated production over one year were quite different - e.g. harvested production predicted with the 2 PDE-based models grew more regularly than in the DEB-IBM. The difference was even stronger for the standing stocks. Average values were equal to 3,517 and 3,244 tons for the 2 PDE-based models and the dynamics were not at all comparable to DEB-IBM. Since it was checked that PDEbased and IBM gave the same results when a simple empirical growth model was used, the difference was related to the use of the DEB equations instead of the empirical equation. Introducing variability in the DEB-IBM yielded several estimations of standing stock and harvested production due to the repeated simulations (Fig. 11). On the whole, they confirmed that individual variability attenuated the dramatic changes of stock and harvested production curves due to rapid oyster growth during spring, but did not modify the shift between the harvested productions simulated with PDE-based model and DEB-IBM.

\section{Discussion}

\subsection{DEB model}

In this paper, we applied an existing DEB model to several existing datasets of environmental parameters (chlorophyll $a$, temperature) and oyster growth in Thau lagoon corresponding to 4 sites, 2 years and 2 cultivation techniques. Most of DEB parameters were estimated from independent datasets using comprehensive studies of oyster growth and ecophysiology under controlled food and temperature conditions (Pouvreau et al., 2006) and literature (Van der Veer et al., 2006). Only two parameters were calibrated: the shape parameter which was used to convert fresh tissue mass into shell length, and the half saturation coefficient which controlled the functional response of assimilation to food concentration. A better prediction of mass and length was obtained when these 2 parameters were fitted on each dataset separately. 
The shape parameter was slightly different from the expected value for the datasets related to the second year growth experiment. The existence of a single value for all individuals of the same species may be questioned, since populations (as here) have different origins. However, the differences we found between datasets are much lower than the differences between species. Van der Veer et al. (2006) reported a value of 0.381 for cockles and 0.287 for mussels. Besides, the shape parameter is only used as a conversion coefficient and is not essential for the DEB model, however it is needed for the population dynamics model since the harvesting rule is dealing with individual total mass which is strongly correlated to shell length. As for the half saturation coefficient $X_{k}$, there were some differences between surveys, sites and categories - without a clear effect of one of these factors. Using a unique $X_{k}$ therefore yielded a lower goodness-of-fit but it was comparable to the empirical equation used by Gangnery et al. (2003). We found a correlation between $X_{k}$ and chlorophyll a averaged on each site and year (not shown), which shows that the functional response did not capture all the influence of food concentration on oyster growth. It may be due to the existence of other food sources like detritus which are often introduced in growth model (Barillé et al., 1997; Grant and Bacher, 1998; Scholten and Smaal, 1998; Duarte et al., 2003) and it was the explanatory variable retained by Gangnery et al. (2003). Several trials were made to consider POM as a single food source or to combine chlorophyll a and POM into a more elaborate functional response but none attempt was conclusive. Other authors also make the same assumption of a single food source (Pastres et al., 2001; Ren and Ross, 2001) or a simple Holling type II function as a generic response of filter feeders similar to ours (Dowd, 1997). In Thau lagoon, POM concentrations are usually low compared to other coastal areas where oyster are cultured, and chlorophyll $a$ is probably the main food source even though no direct measurement or comparison of assimilation of chlorophyll $a$ and POM are available to support this assumption. Compared to other ecosystems however, the dynamics of Thau lagoon shows a low temporal variability and the simplification of functional response would therefore remain acceptable.

Our results showed that the DEB model was a powerful tool to simulate oyster growth in a natural environment because 1) parameters were estimated on independent datasets (Van der Veer et al., 2006) and 2) validation was achieved for different experimental and in situ conditions (Pouvreau et al., 2006). To our knowledge its application to a comprehensive dataset in a real ecosystem was not achieved before. DEB model relies upon some general principles - e.g. energy is allocated to storage, reproduction and growth, assimilation is function of a surface, energy costs are functions of body volume, temperature effects are the same for all physiological rates - which are consistent with general observations and decrease the number of parameters. All other models applied to shellfish appear more empirical to some extent. Ren and Ross (2001) developed a model of oyster growth based on scope for growth and applied it successfully to different ecosystems but in most studies growth predictions are generally not fully validated on experimental or detailed field datasets (Kobayashi et al., 1997) or are restricted to a single ecosystem (Barillé et al., 1997; Grant and Bacher, 1998; Scholten and Smaal, 1998; Gangnery et al., 2004a, b). DEB has therefore several advantages compared to other models: a small number of parameters is 
needed, it is generic and can be applied to different species and ecosystems with minor changes and it is robust and consistent. Only 16 parameters were used but 4 were added to modulate the potential influence of low or high temperature on physiological rates. With their empirical equation Gangnery et al. (2003) used 12 parameters to predict dry tissue mass, shell length and total mass. However, one advantage of their model was that they only needed one equation with 4 parameters to predict total mass in the PDE-based model. On the other hand, even though the modelling methodology could be successfully repeated, parameters had to be estimated again for mussel using the same field survey (Gangnery et al., 2004b). Due to its genericity, application of DEB model would require less effort in the field and need only to identify and monitor food sources. DEB predictions are also consistent with general features of individual growth. In a steady environment, it is proven that growth is equivalent to von Bertalanffy's equation and that the growth rate constant can be estimated from DEB parameters (Kooijman, 2000; Van der Veer et al., 2006). This result guarantees that individual mass or size will not go beyond a maximum value. This property is not met by Gangnery et al. (2003, 2004b) whose model predicts an infinite growth - which would not affect the relevance of their harvested production forecast, but represents a methodological limitation of such an approach. The last advantage of the new model compared to Gangnery et al. (2004a) is that it is a step towards the assessment of interactions between oyster population and phytoplankton concentration in the ecosystem. The effect of oysters on the ecosystem dynamics could therefore be assessed by deriving biodeposition and excretion from the existing equations of ingestion, assimilation and maintenance. This would bridge the gap between existing ecosystem (Chapelle et al., 2000) and oyster growth models.

\subsection{Population model}

The development of a population model using IBM technique was straightforward and the only parameter we had to choose carefully was the seeding time interval to which the number of cohorts is related. With a limited number of cohorts, the dynamics of the standing stock and the harvested production that were obtained before with the PDE-based model could be reproduced. The coupling between IBM and either the empirical growth equation or the DEB model proves that IBM is much more flexible than the PDE-based model. We are aware that much more trajectories would be necessary if we wanted to assess accurate size distributions in order to calibrate the DEB-IBM predictions like Gangnery et al. (2004a), but the management of ten times the actual number of cohorts would still be feasible. The other advantage is that any type of growth equation can be implemented in an IBM. It would therefore be very easy to apply to mussel populations in Thau lagoon using the same DEB model with the appropriate set of parameters (Van der Veer et al., 2006).

We checked that IBM and PDE-based model coupled to the same empirical growth equation would give the same results in the case of no variability between individuals. This was achieved by decreasing the numerical diffusion in the PDE-based model (see Gangnery et al. $(2001,2004 a)$ for 
further explanation), ana accounting for inter-individual variability. Computations showed that it has an effect on estimations of standing stock and harvested production of about $10 \%$. Growth variability is a key issue for ecological reason (it plays a role in the evolution of the population and the trophic interactions with other species) and practical reasons related to marketable size and efficiency of rearing techniques. It has been reported for mussel culture on "bouchot" (Boromthanarat et al., 1988) and most often neglected in population models of filter feeders. Use of a PDE was an advantage for including variability in the population dynamics, since numerical diffusion completed by a diffusion coefficient allowed to reproduce the observed growth variance (Gangnery et al., 2004a). With a DEB-IBM, two strategies can be examined. In a simple IBM of mussel population dynamics, Thomas (2004) derived a statistical relationship between size variance and mean from growth measurements and computed the variance for each cohort. Size distribution of the total population was constructed by superimposing the size distributions of all the cohorts, assuming normal distributions. Wyszomirski et al. (1999) related variability to assimilation and respiration rates in a simple model of competition between individuals and randomly drew parameters to simulate a lot of individual trajectories. The first solution is easy to apply and is generally appropriate when growth rate is constant - e.g. variance and growth are simple functions of time. The second solution is attractive because it is related to the variability of physiological responses, but is limited by the small amount of information on such variability. We assumed that most of the variability was related to feeding. Introducing $X_{k}$ normal distribution in the functional response of assimilation to food concentration allowed to reproduce observed growth variability. Simulations with growth variability therefore confirmed that variability plays a role in the population dynamics and has to be taken into account to assess standing stock and harvested production.

Comparison between PDE-based model and DEB-IBM showed that the population dynamics was very sensitive to the growth equation. Both empirical and DEB growth models reproduced observed growth but small differences between the 2 models resulted in a large difference of population dynamics - assessed in our study through standing stock and harvested production. In the DEB model, shell length and total mass remained constant during winter, as opposed to a slight increase in the empirical growth. This difference would explain why the harvested production predicted by the IBM was delayed compared to the PDE-based model. As a consequence, more oysters would stay in the population and the standing stock would keep on growing with the arrival of seeded animals. As long as estimation of annual harvested production is the primary objective of the population model, model prediction would still be acceptable but the sensitivity of the population dynamics to individual growth is problematic. Including growth variability compensated only partly the null winter growth and changed the harvest timing - see the comparison made with the PDE-based model and DEB-BM with/without variability. As a consequence, production data would be useful to validate the population model.

\section{References}


Barillé, L., Héral, M., Barillé-Boyer, A.L., 1997. Ecophysiological deterministic model for Crassostrea gigas in an estuarine environment. Aquat. Living Resour. 10, 31-48.

Barbeau, M.A, Caswell, H., 1999. A matrix model for short-term dynamics of seeded populations of sea scallops. Ecol. Appl. 9, 266-287.

Batchelder, H., Edwards, C., Powell, T., 2002. Individual-based models of copepod populations in coastal upwelling regions: implications of physiologically and environmentally influenced diel vertical migration on demographic success and nearshore retention. Prog. Oceanogr. 53, 307-333.

Beadman, H.A., Willows, R.I., Kaiser, M.J., 2002. Potential applications of mussel modelling. Helgol. Mar. Res. 56, 76-85.

Borja, A., Bald, J., 2002. Proposal for a management model for clam (Ruditapes decussatus) exploitation in the Basque country (Northern Spain). Proc. Int. Conf. Sustainable Management of Coastal Ecosystems. Lisbon, Spain, pp. 129-140.

Boromthanarat, S., Deslous-Paoli, J.M., 1988. Production of Mytilus edulis L. reared on bouchots in the Bay of Marennes-Oléron: Comparison between two methods of culture. Aquaculture 72, 255-263.

Brody, S., 1945. Bioenergetics and growth. Rheinhold, New York.

Cardoso, J.F.M.F., Van der Meer, J., Van der Veer, H.W., 2001. Interspecies comparison of energy flow in some North Atlantic bivalve species by means of dynamic energy budget. ICES C.M./J 43.

Chapelle, A., Menesguen, A., Deslous-Paoli, J.-M., Souchu, P., Mazouni, N., Vaquer, A., Millet, B., 2000. Modelling nitrogen, primary production and oxygen in a Mediterranean lagoon. Impact of oysters farming and inputs from the watershed. Ecol. Model. 127, 161-181.

De Roos, A. M., 1988. Numerical methods for structured population models: the Escalator Boxcar Train. - Num.Meth. Part. Diff. Eqs. 4, 173-195.

De Roos, A.M., McCauley, E., Nisbet, R.M., Gurney, W.S.C., Murdoch, W.W., 1997. What individual life histories can (and cannot) tell about population dynamics. Aquat. Ecol. 31, 3745.

De Roos, A.M., Persson, L., 2001. Physiologically structured models - from versatile technique to ecological theory. Oikos 94, 51-71.

DeAngelis, D.L., Gross, L.J., 1992. Individual-based models and approaches in ecology: populations, communities and ecosystem. Chapman \& Hall, New York.

Dekshenieks, M.M., Hofmann, E.E., Klinck, J.M., Powell, E.N., 2000. Quantifying the effects of environmental changes on an oyster population: a modeling study. Estuaries 23, 593-610.

Dowd, M., 1997. On predicting the growth of cultured bivalves. Ecol. Model. 104, 113-131.

Duarte, P., Meneses, R., Hawkins, A.J.S, Zhu, M., Fang, J., Grant, J., 2003. Mathematical modelling to assess the carrying capacity for multi-species culture within coastal waters. Ecol. Model. 168, 109-143. 
Gangnery, A., Bacher, C., Buestel, D., 2001. Assessing the production and the impact of the cultivated oysters in the Thau lagoon (Mediterranee, France) with a population dynamics model. Can. J. Fish. Aquat. Sci. 58, 1012-1020.

Gangnery, A., Chabirand, J.M., Lagarde, F., Le Gall, P., Oheix, J., Bacher, C., Buestel, D., 2003. Growth model of the Pacific oyster, Crassostrea gigas, cultured in Thau Lagoon (Méditerranée, France). Aquaculture 215, 267-290.

Gangnery, A., Bacher, C., Buestel, D., 2004a. Modelling oyster population dynamics in a Mediterranean coastal lagoon (Thau, France): sensitivity of marketable production to environmental conditions. Aquaculture 230, 323-347.

Gangnery, A., Bacher, C., Buestel, D., 2004b. Application of a population dynamics model to the Mediterranean mussel, Mytilus galloprovincialis, reared in Thau Lagoon (France). Aquaculture 229, 289-313.

Grant, G., Bacher, C., 1998. Comparative models of mussel bioenergetics and their validation at field culture sites. J. Exp. Mar. Biol. Ecol. 219, 21-44.

Hallam, T.G., Lassiter, R.R., Li, J., McKinney, W., 1988. Physiologically structured population models in risk assessment. In: Ricciardi L.M. (Ed.), Biomathematics and related computational problems, Kluwer Academic Publishers, Dordrecht, 760 pp.

Kobayashi, M., Hofmann, E.E., Powell, E.N., Klinck, J.M., Kusaka, K., 1997. A population dynamics model for the Japanese oyster, Crassostrea gigas. Aquaculture 149, 285-321.

Kooijman, S. A. L. M., 2000. Dynamic energy and mass budgets in biological systems, Cambridge University Press, Cambridge, $2^{\text {nd }}$ Edition.

McDermot, M., Rose, K. A., 2000. An individual-based model of lake fish communities: application to piscivore stocking in Lake Mendota. Ecol. Model. 125, 67-102.

Pastres, R., Solidoro, C., Cossarini, G., Melaku Canu, D., Dejak, C., 2001. Managing the rearing of Tapes philipinarum in the lagoon of Venice: a decision support system. Ecol. Model. 138, 213-245.

Pouvreau, S., Bourles, Y., Lefebvre, S., Gangnery, A., Alunno-Bruscia, M. Application of a dynamic energy budget model to the Pacific oyster, Crassostrea gigas, reared under various environmental conditions. J. Sea Res. (this volume).

Ren, J. S., Ross, A.H., 2001. A dynamic energy budget model of the Pacific oyster Crassostrea gigas. Ecol. Model. 142, 105-120.

Ross, A. H., Nisbet, R.M., 1990. Dynamic models of growth and reproduction of the mussel Mytilus edulis L. Func. Ecol. 4, 777-787.

Rueda, J.L., Smaal, A.C., Scholten, H., 2005. A growth model of the cockle (Cerastoderma edule L.) tested in the Oosterschelde estuary (The Netherlands). J. Sea Res., in press.

Savina, M., 2004. Modélisation écologique des populations de palourdes roses (Paphia rhomboïdes) et d'amandes de mer (Glycymeris glycymeris) en Manche. Thèse de Doctorat, Université Aix-Marseille II, 191 pp. 
Scholten, H., Smaal, A.C., 1998. Responses of Mytilus edulis L. to varying food concentrations: testing EMMY, an ecophysiological model. J. Exp. Mar. Biol. Ecol. 219, 217-239.

Thomas, Y., 2004. Etude de la croissance de Crassostrea gigas et Mytilus edulis en Baie du Mont Saint Michel et dynamique de la population de moules exploitées sur bouchots. Mémoire de DEA Exploitation Durable des Ecosystèmes Littoraux, Université de La Rochelle, 52 pp.

Van der Meer, J. 2006. An introduction to Dynamic Energy Budget (DEB) models with special emphasis on parameter estimation. J. Sea Res. (this volume)

Van der Veer, H.W., Cardoso, J.F.M.F., Van der Meer, J., 2006. Estimation of DEB parameters for various North Atlantic bivalve species. J. Sea Res. (this volume).

Van der Veer, H.W., Kooijman, S.A.L.M., Van der Meer, J., 2001. Intra- and interspecies comparison of energy flow in North Atlantic flatfish species by means of dynamic energy budgets. J. Sea Res. 45, 303-320.

Van Haren, R.J.F., Kooijman, S.A.L.M., 1993. Application of a dynamic energy budget model to Mytilus edulis (L.). Neth. J. Sea Res. 31, 119-133.

Wyszomirski, T., Wyszomirska, I., Jarzyna, I., 1999. Simple mechanisms of size distribution dynamics in crowded and uncrowded virtual monocultures. Ecol. Model. 115, 253-273. 
Table 1. List of DEB parameters

\begin{tabular}{|c|c|c|c|c|}
\hline Parameters & Symbol & Unit & Value & Reference \\
\hline Half saturation coefficient & $X_{K}$ & $\mu g . I^{-1}$ & - & This study \\
\hline Max. surf. area-specific assimilation rate & $\left\{\dot{p}_{A m}\right\}$ & $\mathrm{J} . \mathrm{cm}^{-2} \cdot \mathrm{d}^{-1}$ & 560 & $\begin{array}{l}\text { Van der Veer et al. } \\
\qquad(2006)\end{array}$ \\
\hline Volume-specific maintenance costs & {$\left[\dot{p}_{M}\right]$} & $\mathrm{J} . \mathrm{cm}^{-3} \cdot \mathrm{d}^{-1}$ & 24 & $\begin{array}{l}\text { Van der Veer et al. } \\
\qquad(2006)\end{array}$ \\
\hline Maximum storage density & {$\left[E_{M}\right]$} & $\mathrm{J} . \mathrm{cm}^{-3}$ & 2295 & $\begin{array}{l}\text { Van der Veer et al. } \\
\qquad(2006)\end{array}$ \\
\hline Volume-specific cost for structure & {$\left[E_{G}\right]$} & $\mathrm{J} . \mathrm{cm}^{-3}$ & 1900 & $\begin{array}{l}\text { Van der Veer et al. } \\
\qquad(2006)\end{array}$ \\
\hline Structural volume at puberty & $V_{p}$ & $\mathrm{~cm}^{-3}$ & 0.4 & Pouvreau et al. (2006) \\
\hline $\begin{array}{l}\text { Fraction of energy utilisation rate spent } \\
\text { on maintenance plus growth }\end{array}$ & $\kappa$ & - & 0.45 & $\begin{array}{l}\text { Van der Veer et al. } \\
\qquad(2006)\end{array}$ \\
\hline Shape coefficient & $\delta_{m}$ & - & 0.175 & $\begin{array}{l}\text { Van der Veer et al. } \\
\qquad(2006)\end{array}$ \\
\hline Arrhenius temperature & $T_{A}$ & $\mathrm{~K}$ & 5800 & $\begin{array}{l}\text { Van der Veer et al. } \\
\qquad(2006)\end{array}$ \\
\hline Reference temperature & $T_{1}$ & K & 293 & $\begin{array}{l}\text { Van der Veer et al. } \\
\qquad(2006)\end{array}$ \\
\hline $\begin{array}{l}\text { Lower boundary temperature of the } \\
\text { tolerance range }\end{array}$ & $T_{L}$ & $\mathrm{~K}$ & 281 & $\begin{array}{l}\text { Van der Veer et al. } \\
\qquad(2006)\end{array}$ \\
\hline $\begin{array}{l}\text { Upper boundary temperature of the } \\
\text { tolerance range }\end{array}$ & $T_{H}$ & $\mathrm{~K}$ & 305 & $\begin{array}{l}\text { Van der Veer et al. } \\
\qquad(2006)\end{array}$ \\
\hline $\begin{array}{l}\text { Arrhenius temperature for the rate of } \\
\text { decrease at lower boundary }\end{array}$ & $T_{A L}$ & $\mathrm{~K}$ & 75000 & $\begin{array}{l}\text { Van der Veer et al. } \\
\qquad(2006)\end{array}$ \\
\hline $\begin{array}{l}\text { Arrhenius temperature for the rate of } \\
\text { decrease at upper boundary }\end{array}$ & $T_{A H}$ & $\mathrm{~K}$ & 30000 & $\begin{array}{l}\text { Van der Veer et al. } \\
\qquad(2006)\end{array}$ \\
\hline $\begin{array}{l}\text { Fraction of reproduction energy fixed in } \\
\text { eggs }\end{array}$ & $\kappa_{R}$ & - & 0.6 & $\begin{array}{l}\text { Pouvreau (personal } \\
\text { communication) }\end{array}$ \\
\hline $\begin{array}{l}\text { Energy content of reserves (in ash-free } \\
\text { dry mass) }\end{array}$ & $\mu_{E}$ & $\mathrm{~J}^{\mathrm{mg}} \mathrm{g}^{-1}$ & 17.5 & Brody (1945) \\
\hline $\begin{array}{l}\text { Gonado-somatic threshold for triggering } \\
\text { spawning }\end{array}$ & $R_{G S}$ & $\%$ & 35 & Pouvreau et al. (2006) \\
\hline
\end{tabular}


Table 2. Initial repartition (\%) of the fresh tissue mass into structural volume, reserve and gonad used for simulations of the DEB model.

\begin{tabular}{|l|c|c|c|}
\hline & Structural volume & Reserves & Reproduction \\
\hline Survey 1 - Category 1 & 100 & 0 & 0 \\
\hline Survey 1 - Category 2 & 30 & 70 & 0 \\
\hline Survey 2 - Category 1 & 70 & 30 & 0 \\
\hline Survey 2 - Category 2 & 70 & 30 & 0 \\
\hline
\end{tabular}


Table 3. Optimised values of $X_{k}$ and $\delta_{m}$ given by the model for each simulation.

\begin{tabular}{|l|c|c|c|c|c|c|c|c|}
\hline & \multicolumn{2}{|c|}{ Site 2 } & \multicolumn{2}{c|}{ Site 3 } & \multicolumn{2}{c|}{ Site 4 } & \multicolumn{2}{c|}{ Site 6 } \\
\hline & $X_{K}$ & $\delta_{m}$ & $X_{K}$ & $\delta_{m}$ & $X_{K}$ & $\delta_{m}$ & $X_{K}$ & $\delta_{m}$ \\
\hline $\begin{array}{l}\text { Survey 1 - } \\
\text { Category 1 }\end{array}$ & 2.94 & 0.181 & 2.36 & 0.186 & 2.23 & 0.194 & 2.01 & 0.194 \\
\hline $\begin{array}{l}\text { Survey 1 - } \\
\text { Category 2 }\end{array}$ & 3.02 & 0.172 & 3.1 & 0.174 & 2.9 & 0.158 & 2.72 & 0.177 \\
\hline $\begin{array}{l}\text { Survey 2 - } \\
\text { Category 1 }\end{array}$ & 3.38 & 0.205 & 2.51 & 0.204 & 3.55 & 0.198 & 2.60 & 0.199 \\
\hline $\begin{array}{l}\text { Survey 2 - } \\
\text { Category 2 }\end{array}$ & 3.27 & 0.201 & 3.58 & 0.200 & 3.91 & 0.206 & 3.24 & 0.196 \\
\hline
\end{tabular}




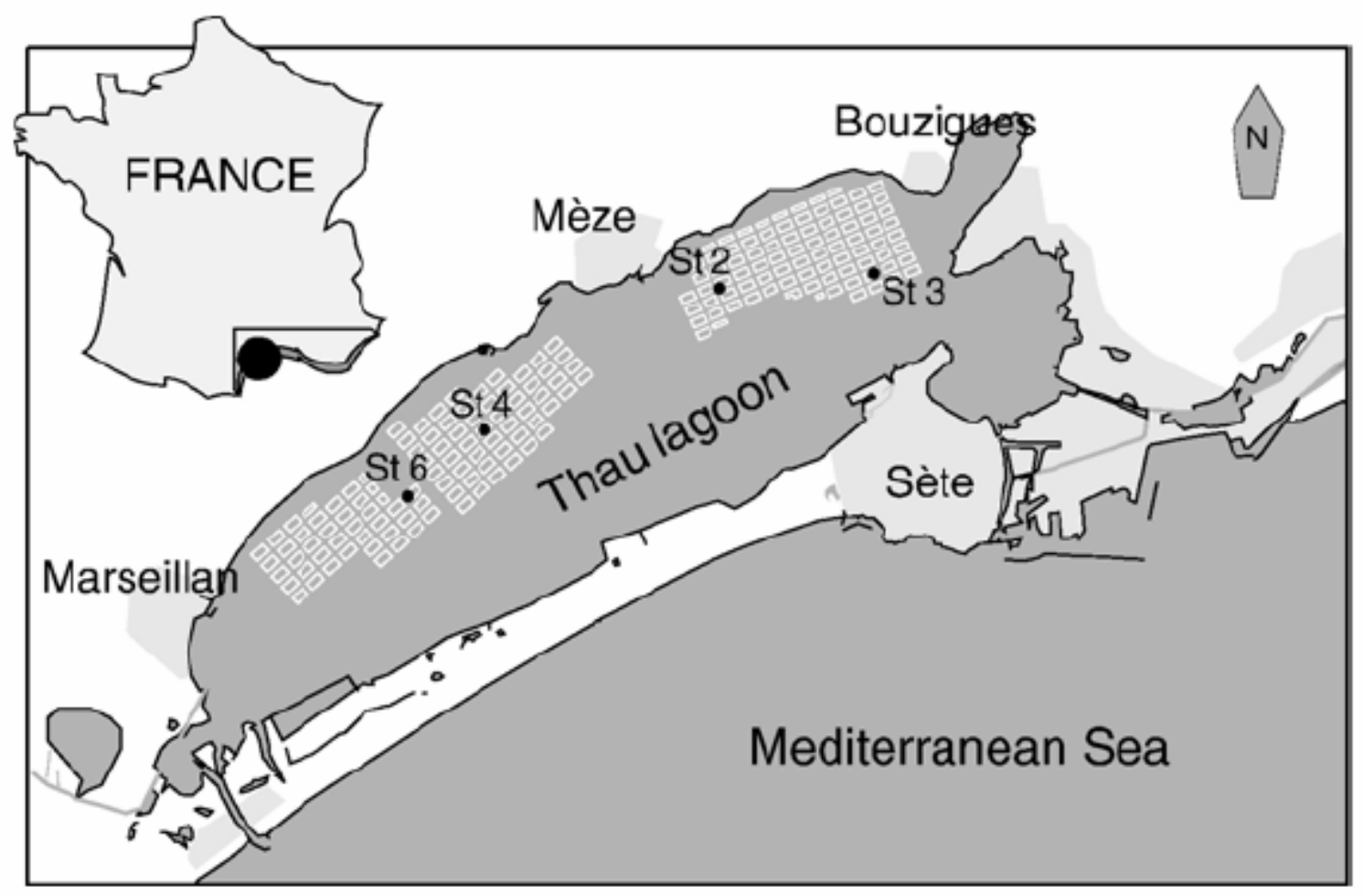

Figure 1. Map of Thau lagoon and study sites 
Site $2 \circ$ Site $3 \Delta \quad$ Site $4 \nabla$ Site $6 \square$
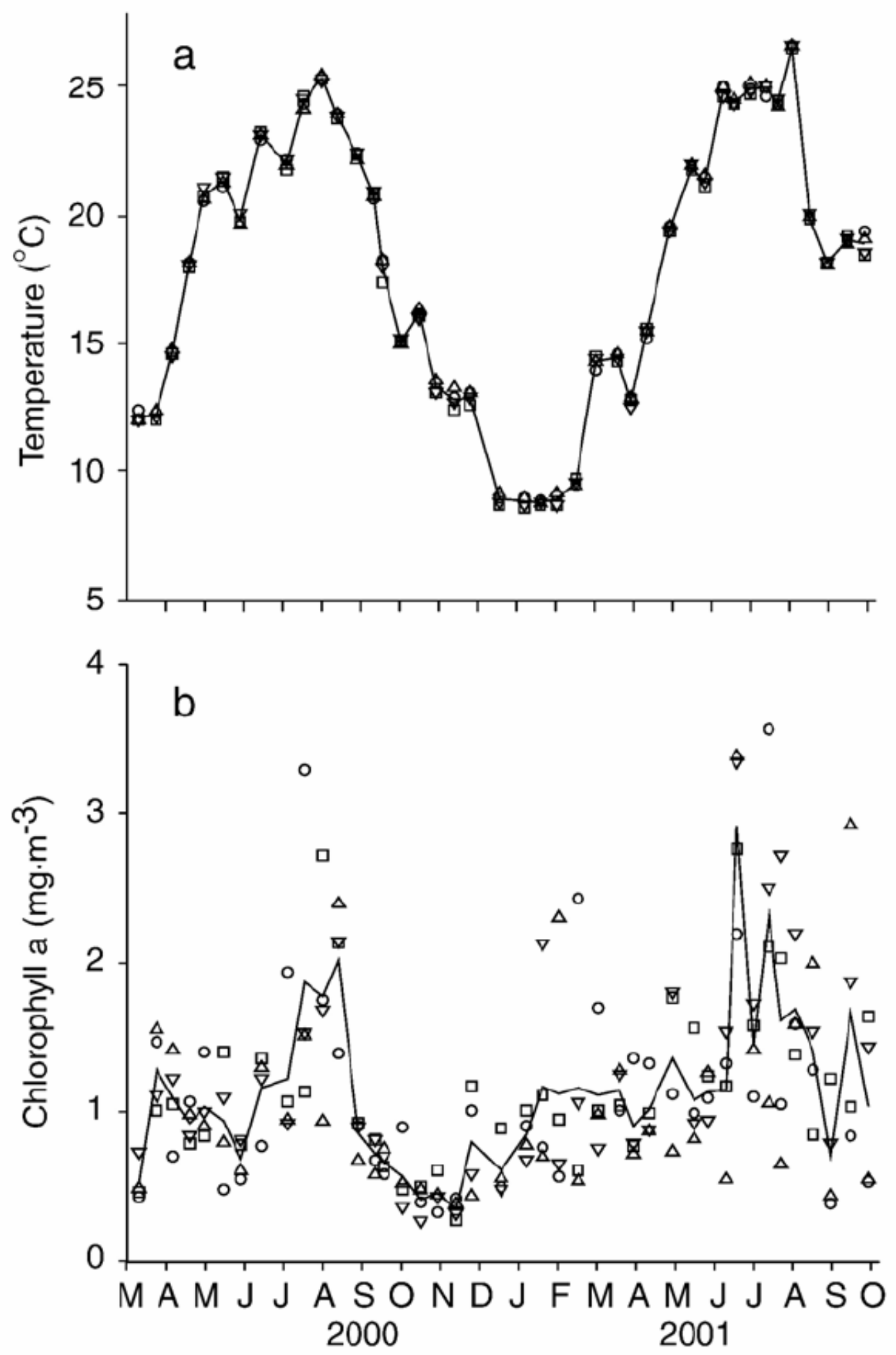

Figure 2. Temperature and chlorophyll a time series for the 4 sites in Thau lagoon. The solid line represents the mean over sites (from Gangnery et al., 2003). 
Site $2 \longrightarrow$ Site $3 \quad \cdots \quad$ Site $4 \quad \cdots \quad-\cdots \cdots$
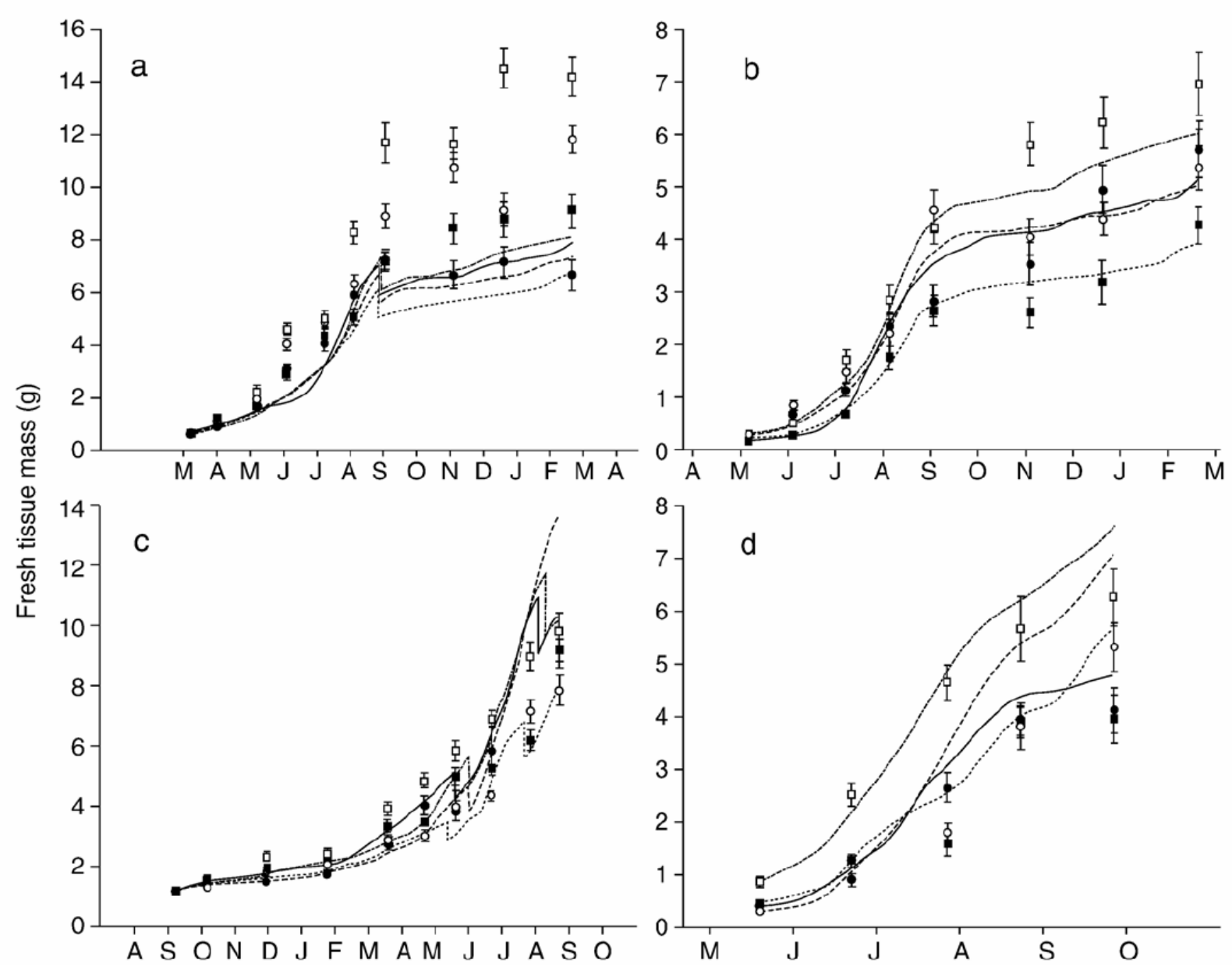

Figure 3. Comparison of fresh tissue mass obtained through DEB simulations (lines) and growth data for a single parameter $X_{k}:$ a) survey 1 x category 1 , b) survey $1 \times$ category 2 , c) survey $2 \times$ category 1, d) survey $2 \times$ category 2 . Mean observed values are presented with their standard error. 
Site $2 \multimap$ Site $3 \cdots \cdots$ Site $4 \multimap-$ Site $6 \cdots \square$
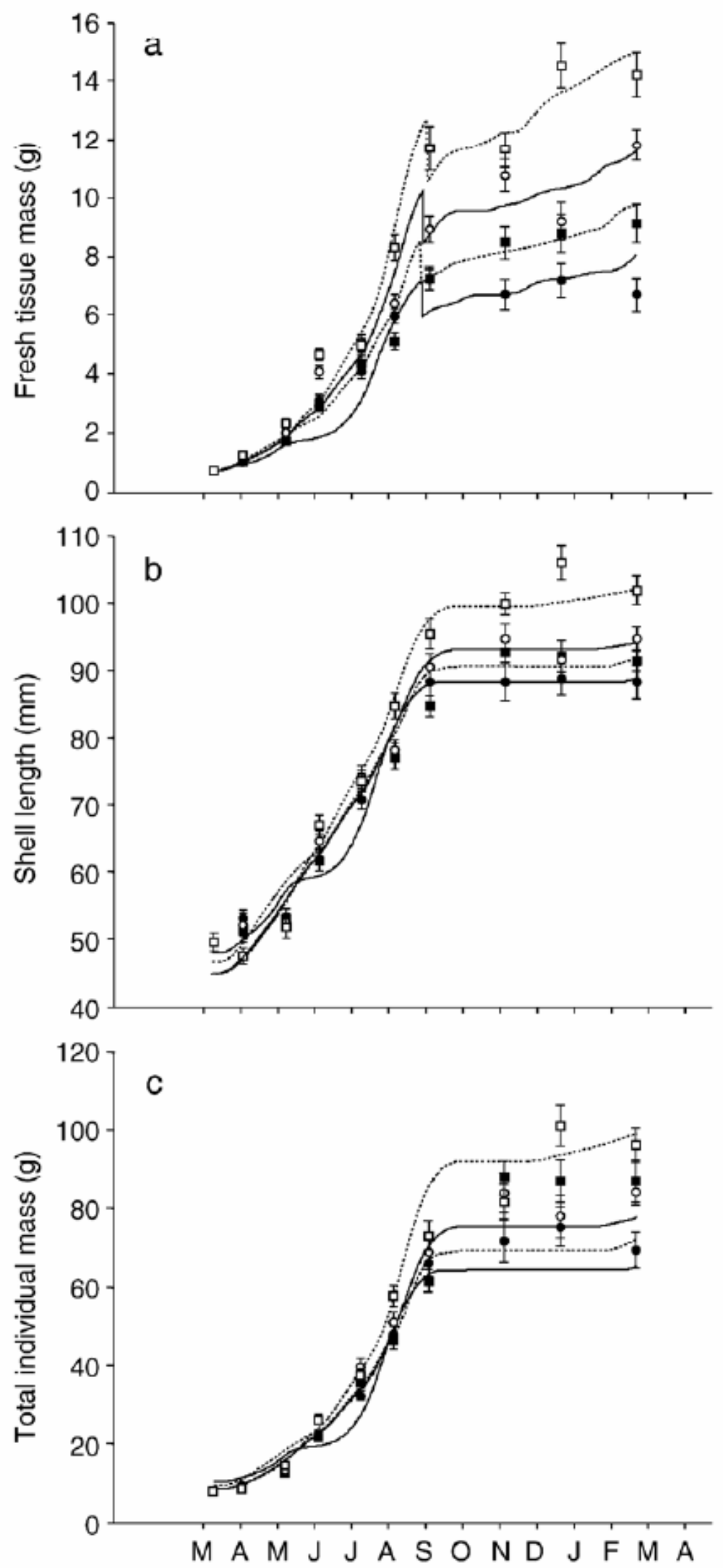

Figure 4. Comparison of DEB simulations (lines) and growth data (symbols) for 16 parameter sets of $X_{k}$ and $\delta_{m}$ : survey $1 \times$ category 1 ; a) fresh tissue mass $\left.(\mathrm{g}), \mathrm{b}\right)$ shell length $\left.(\mathrm{cm}), \mathrm{c}\right)$ individual total mass $(\mathrm{g})$. Mean observed values are presented with their standard error. 

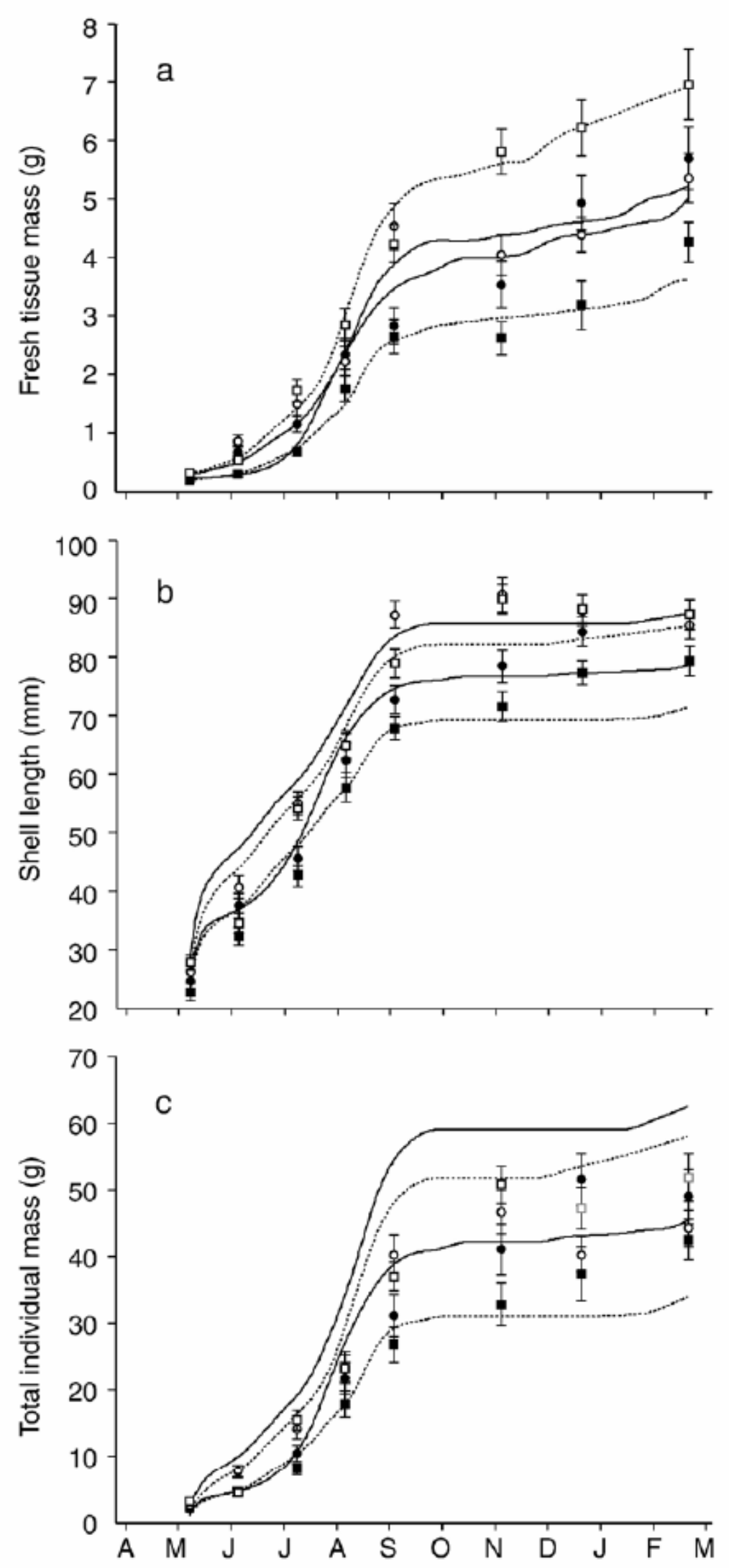

Figure 5. Comparison of DEB simulations (lines) and growth data (symbols) for 16 parameter sets of $X_{k}$ and $\delta_{m}$ : survey $1 \times$ category $2 ;$ a) fresh tissue mass $\left.(\mathrm{g}), \mathrm{b}\right)$ shell length $\left.(\mathrm{cm}), \mathrm{c}\right)$ individual total mass $(\mathrm{g})$. Mean observed values are presented with their standard error. 
Site 2

Site 3

Site $4-0$ Site 6
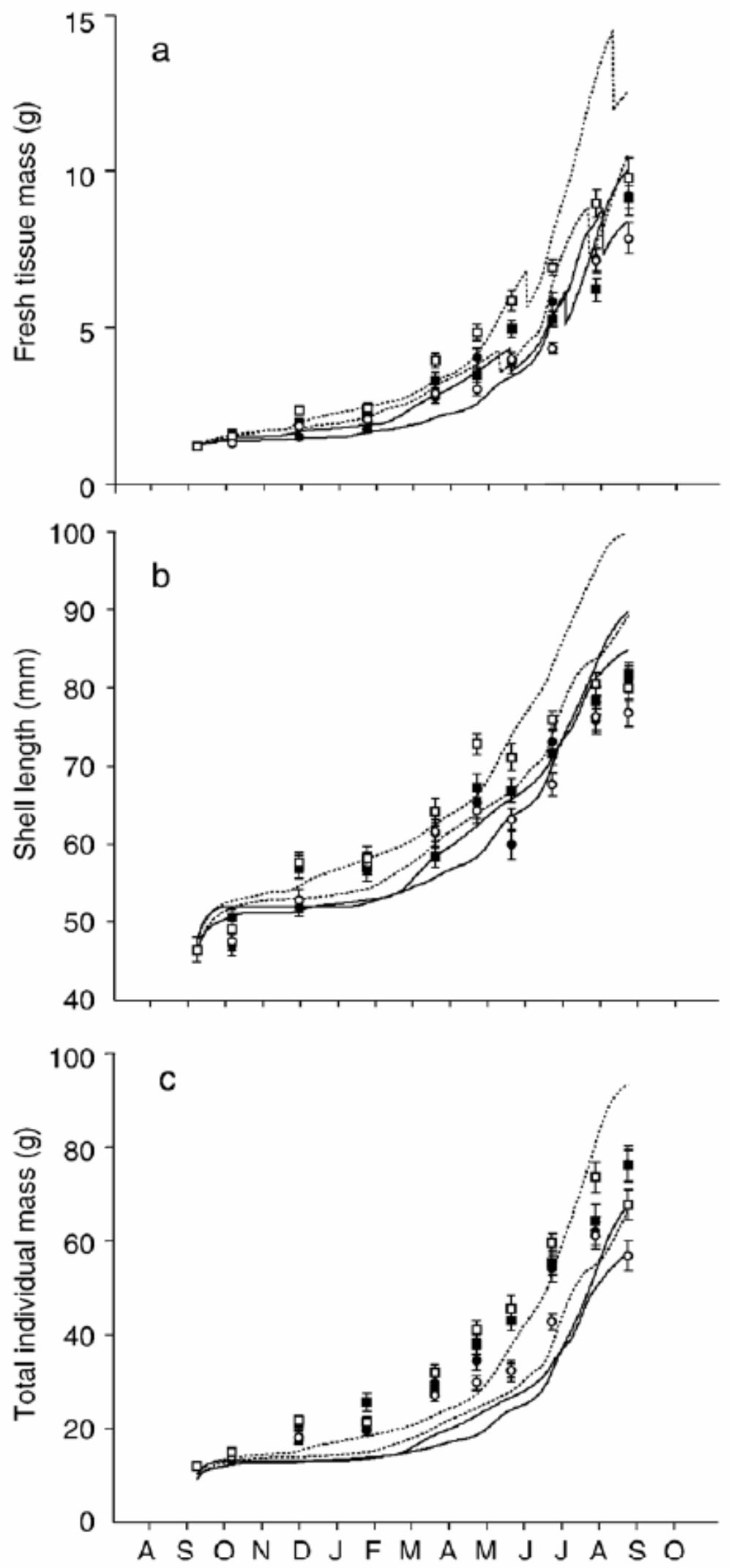

Figure 6. Comparison of DEB simulations (lines) and growth data (symbols) for 16 parameter sets of $X_{k}$ and $\delta_{m}$ : survey $2 \times$ category 1 ; a) fresh tissue mass $\left.(\mathrm{g}), \mathrm{b}\right)$ shell length $\left.(\mathrm{cm}), \mathrm{c}\right)$ individual total mass $(\mathrm{g})$. Mean observed values are presented with their standard error. 

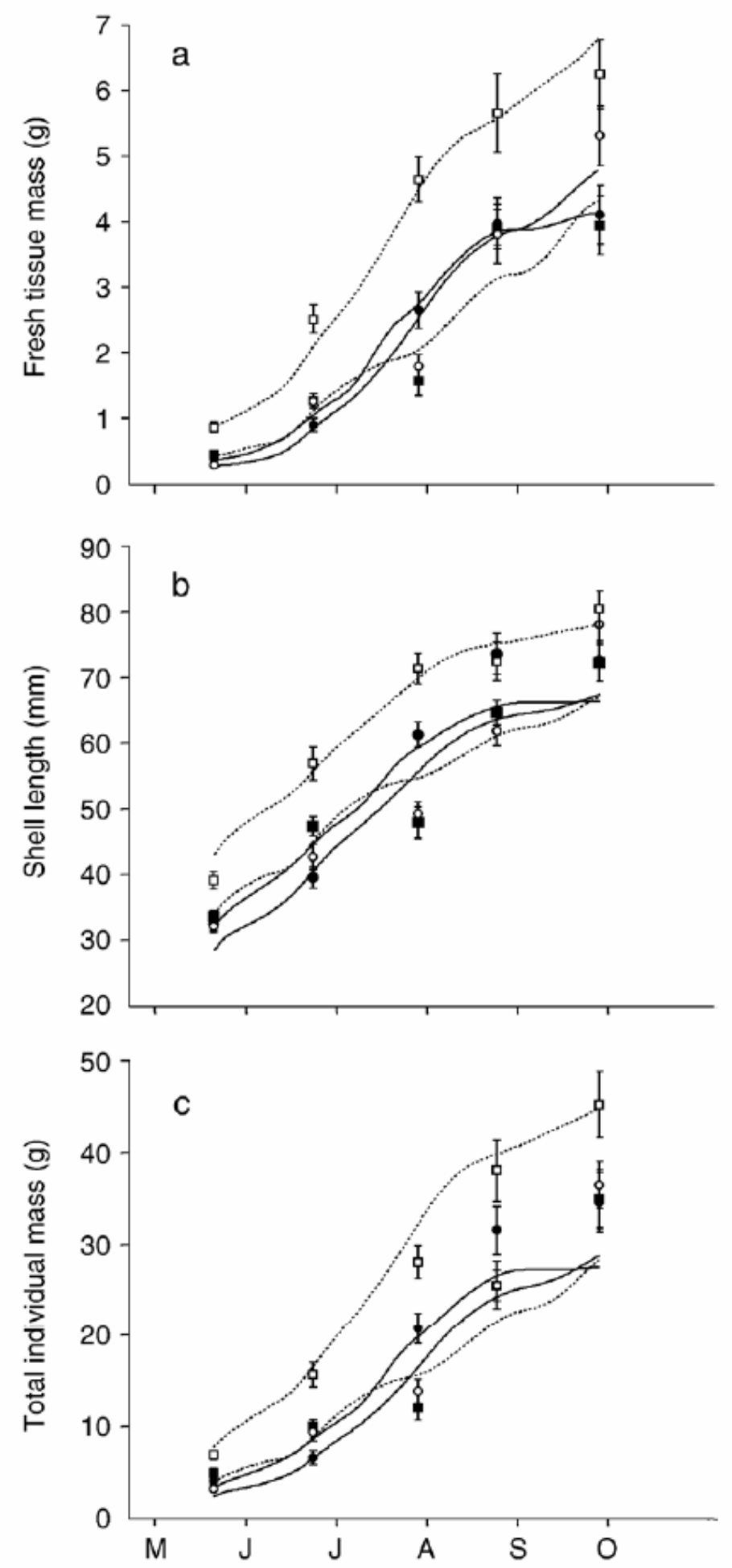

Figure 7. Comparison of DEB simulations (lines) and growth data (symbols) for 16 parameter sets of $X_{k}$ and $\delta_{m}$ : survey $2 \times$ category 2 ; a) fresh tissue mass $\left.(\mathrm{g}), \mathrm{b}\right)$ shell length $\left.(\mathrm{cm}), \mathrm{c}\right)$ individual total mass $(\mathrm{g})$. Mean observed values are presented with their standard error. 

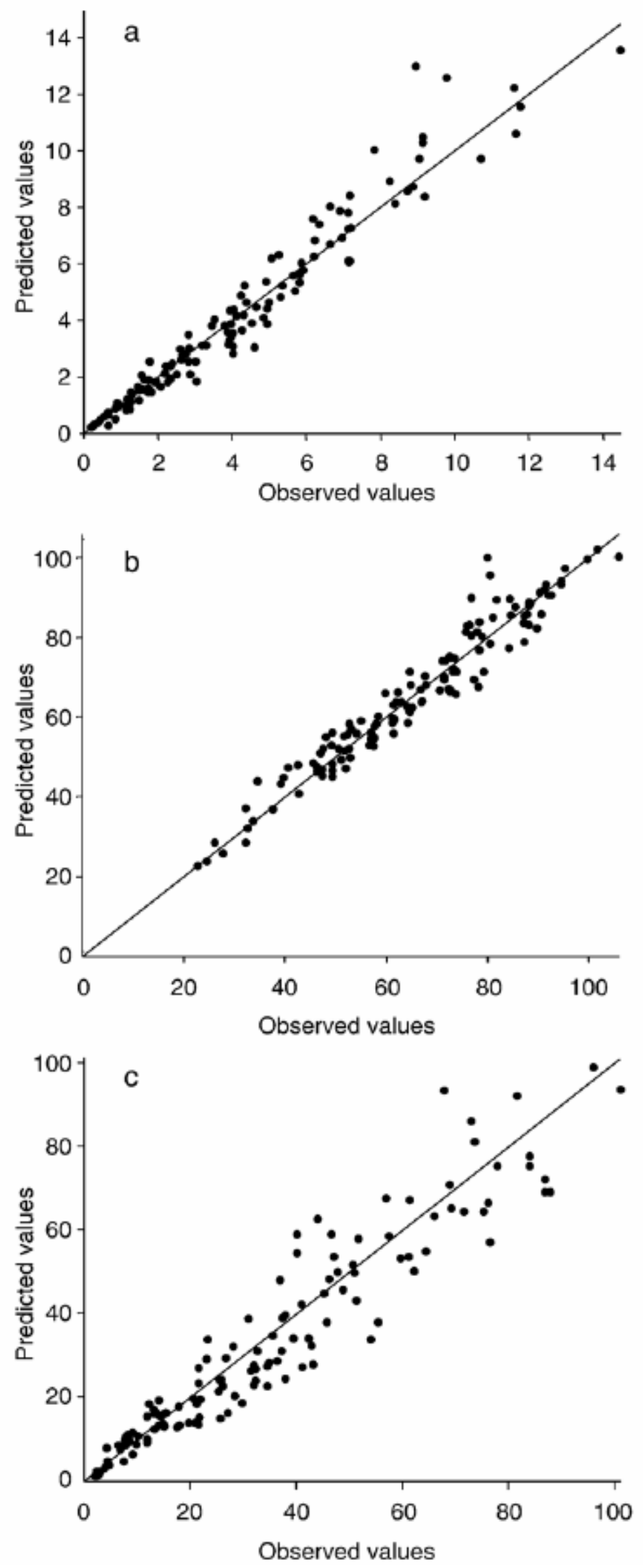

Figure 8. Comparison of correlations between predicted and observed a) fresh tissue mass (g), b) shell length (mm), c) individual total mass (g). 


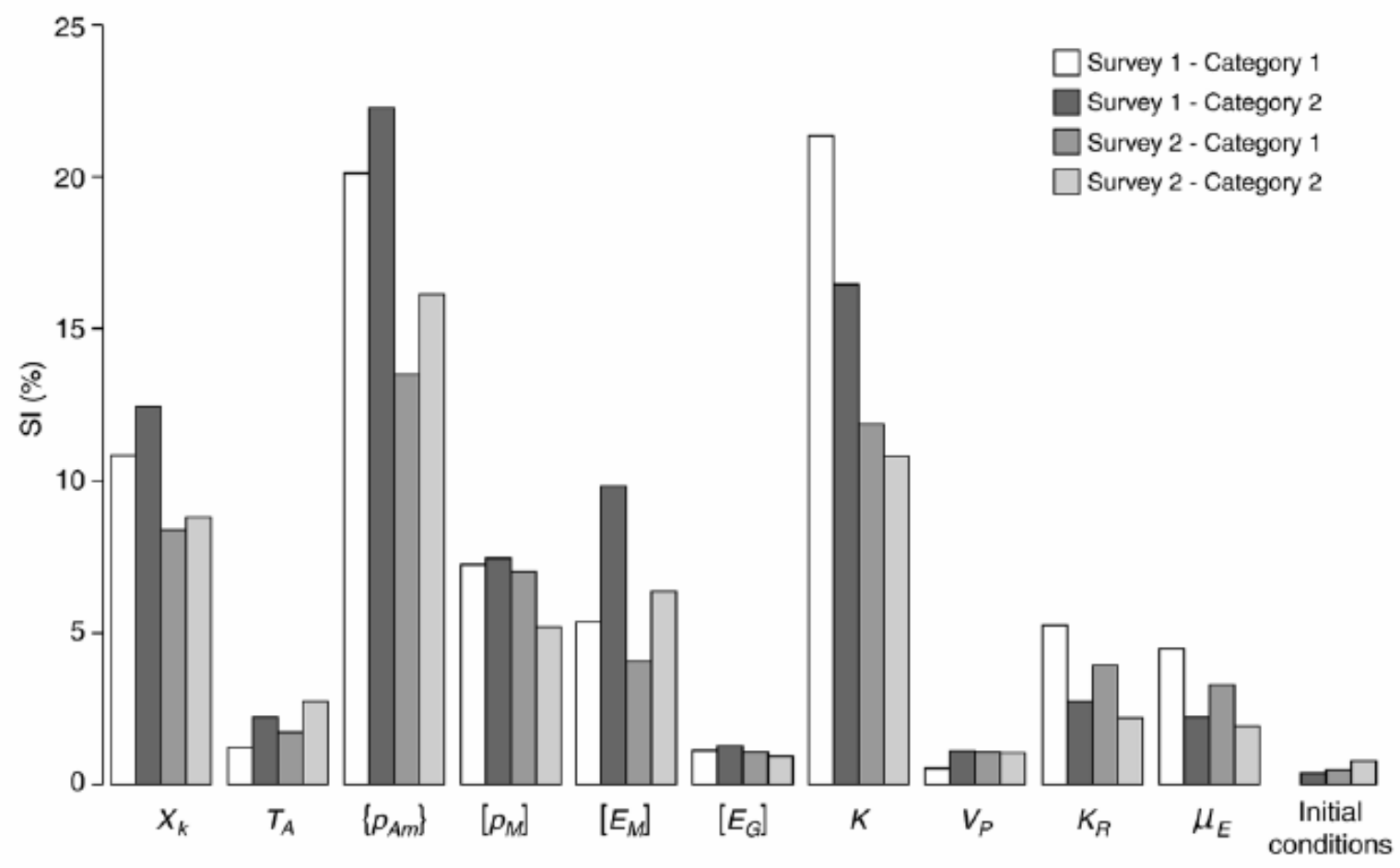

Figure 9. Sensitivity index computed for DEB parameters for each survey and category (see text for details, Eq. 12 and Table 1 for parameter meaning).

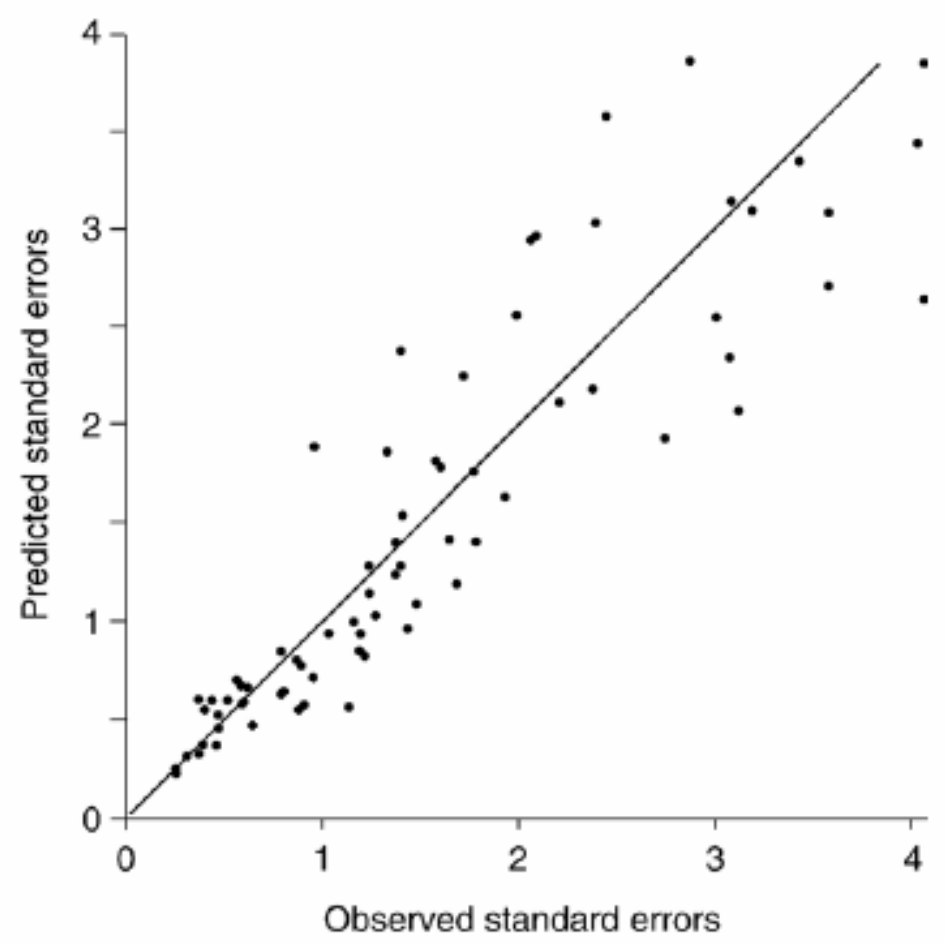

Figure 10. Predicted vs. observed standard deviations of fresh tissue mass (g) for all growth time series. 


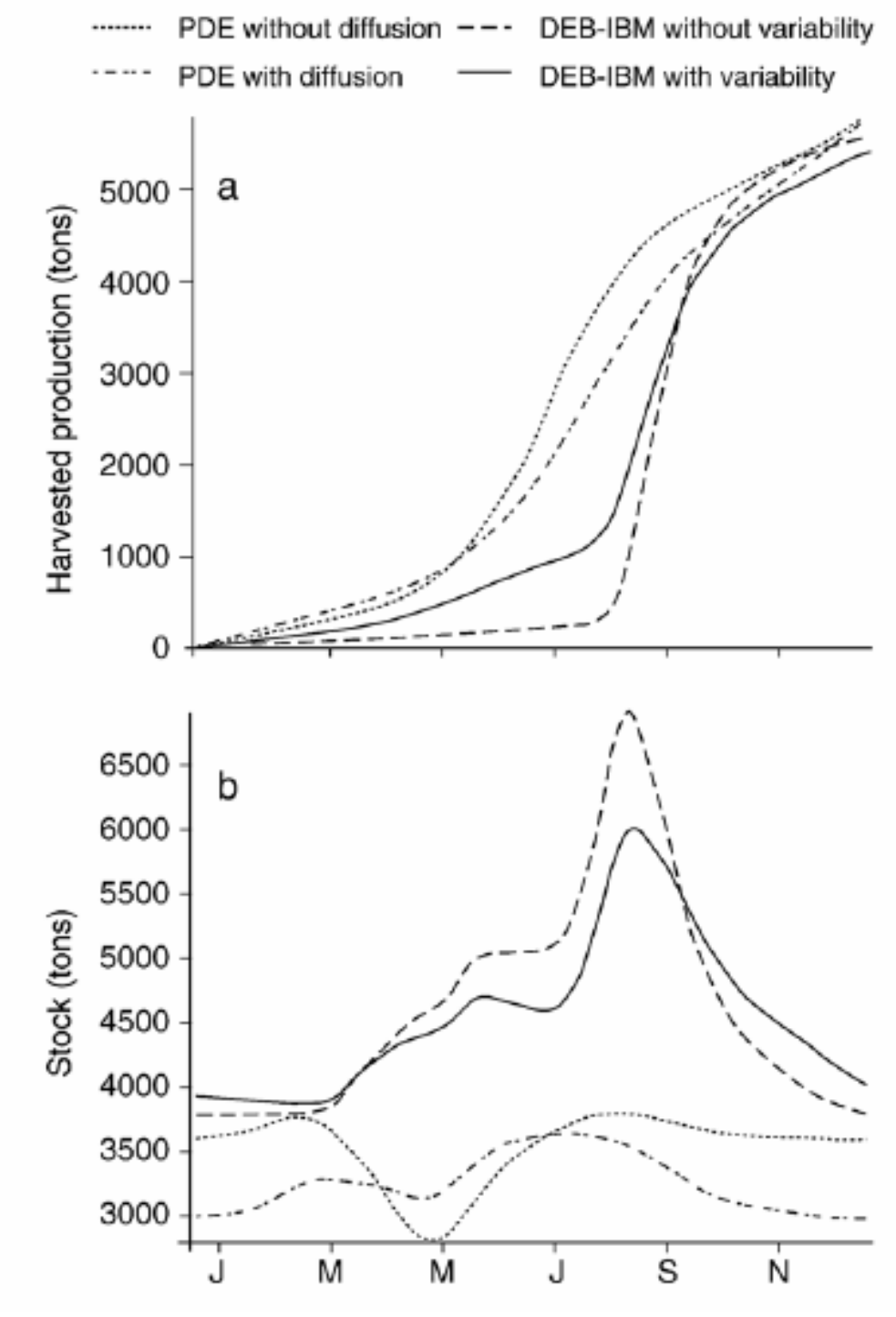

Figure 11. Comparison of PDE-based model and DEB-IBM outputs; a) cumulated harvest (tons), b) standing stock (tons). ... : PDE without diffusion, --- : PDE with diffusion, --- : DEB-IBM without variability, - : DEB-IBM with variability. 